owing to their tendency to stick together it is a common practice to moisten the tips of the fingers with saliva and in so doing infection may be conveyed to the mouth. While isolation of cases and carriers will go a long way to prevent dissemination of the organisms it is mevertheless not sufficient. Cases are bound to pass unrecognised at times and those regarded as clear prove later to be carriers. It is infinitely better to prevent the possibility of this infection, and there is only one way to do this-viz., by preventive inoculation.

The successful application of preventive inoculation to the majority of our soldiers is one of the most brilliant achievements of medicine, and has probably saved more lives than all those lost by violent means. The low incidence of typhoid amongst the troops bears eloquent testimony to the efficacy of antityphoid inoculation, and what I plead for here and for those towns which are liable to be germ centres for the time, is the advocacy by the proper authorities of the value of antityphoid inoculation not for the soldier only, but for the civilian as well.-I am, Sir, yours faithfully,

Reading, Feb. 14th, 1916. ROBERT DONALDSON.

\section{MENTAL DISORDERS AND ATTESTATION.} To the Editor of THE LANCET.

SIR,-Almost daily the very serious question is brought before me as to my duty in reference to the fitness of nervous people for military service. If I had not seen so many cases at the various hospitals for the wounded and invalided soldiers I should have had more hesitation in writing on this subject, but I have come across so many men invalided, in consequence of nervous or mental breakdowns, who, in my opinion, ought never to have been sent to the front. First, I have been asked to give certificate of fitness by men really anxious to serve, who have very slight attacks of petit mal. Naturally I have declined to pass sueh as fit. In other cases I have been consulted by men who, having had more than one attack of insanity, have felt very sensitive because their companions looked upon them as shirkers, and in these cases the question was more difficult because if not allowed to serve they worry and look upon themselves as suspects; this suspicion producing sleeplessness and general ill-health which might readily lead to a fresh breakdown. In these cases, as a rule, I object to their serving in active military work, but encourage munition and other labour.

I think it a safe rule to make that a young man who has had an acute attack of mental disorder within three years should be kept from active service, while if he has had more than one attack he should be rejected. Some of the most difficult cases which $I$ have had to report on have been men who some years before have had serious and prolonged mental disorder, due to overwork or to special strain. Many of these appear to be quite strong, are themselves afraid of breaking down, and also afraid of being thought cowardly. As a rule I prefer to refer such men to the doctors who have had to deal with them in the interval of health. As I have said, it is a serious thing to send men into active service who run real risks of breaking down. The notion that the training will "buck up" the men I have not found to be true. I have in my experience, however, to report that I have known definitely "defectives" who have proved valuable Army Service men or motor drivers.

To sum up my experience, I think it very risky to send any young man who has had a distinct attack of insanity, however well he is at present. I think that there is serious risk for many who hare broken down in former years with mentel strain. I recognise the risk, however, of over-sensitire neurotics feeling they are looked upon as shirkers. Yet I have found certain defectives as quite efficient in non-military work.

I am, Sir, yours faithfully, GEO. H. SaVAGE, M.D., F.R.C.P.

Deronshire-place, W., Feb. 14th, 1916.

\section{CLINICAL THERMOMETRY.}

To the Editor of THE LANCET.

SIR,- In the very full and otherwise apparently complete bibliography of "Clinical Thermometry" appended to the first part of Professor Sims Woodhead's and Mr. Varrier-Jones's investigations on this subject, published in THE LANCET of Jan. 22nd, I regret to find no mention of the late Dr. Thomas Wrigley Grimshaw's classical paper on the Value of Thermometric Observations in Typhus Fever. That paper was a thesis for the degree of Doctor of Medicine in the University of Dublin, and was read before the University on March 4th, 1867. It was published in the number of the Dublin Quarterly Journal of Medical Science for May, 1867 (vol. xliii., No. 86, New Series, p. 313).

I am sure it is necessary only to call the authors' attention to the omission to have it rectified for the sake of the memory of a distinguished Irish pioneer in modern clinical thermometry. The names of other Irish physicians who devoted attention to the sub. ject may be found in the annual reports of the Cork Street Fever Hospital and House of Recovery, Dublin, published in the early decades of the nineteenth century.

I am, Sir, yours faithfully, Dublin, Feb. 15th, 1916 . JoHN W. MOORE, M.D. Dub., F.R.C.P.I,

\section{FUNCTIONAL NERVE DISEASE.}

\section{To the Editor of THE LANCET.}

SIR,-It is becoming more than a little amusing to notice how you have only to whisper the word "psycho-analysis" and certain people at once see red. My paper dealt with the psychical effects of modern fighting, but it contained the obnoxious term, and hence this correspondence. How strange it is that those who still reprobate psycho-analysis and the sexual etiology of the neuroses can remain blind to what must long have been recognised by every thoughtful reader of your paper-namely, that the sexual instinct is clean and pure. It will not do nowadays to dress it up in mid.Victorian prejudices as a repulsive and disreputable bogie to affright our intelligence.

It is due to your readers to add, though I dislike having to say it, that the description of psychoanalysis which Dr. Armstrong-Jones offers for their acceptance is a travesty of the facts.

I am, Sir, yours faithfully,

Wimpole-street, W., Feb. 12th, 1916. DAVID FoRsYTH

\section{INJECTIONS OF PERMANGANATE OF POTASH IN ALBUMINURIA. \\ To the Editor of THE LANCET.}

SIR,-In The LanceT of July 31st, 1915. (p. 219), there is an article on this subject which prompts.me to make the following remarks. During the last 12 months I have seen one case of uræmia and three of albuminuria with general dropsy successfully treated with hypodermic injections of permanganate of 